\title{
Políticas de inovação em nova chave
}

\author{
GLAUCO ARBIX I e ZIL MIRANDA II
}

\section{Introdução}

A FUSÃO entre as crises econômica, moral e política corrói a capacidade de articulação do Estado brasileiro. Mais ainda, enquanto um grande número de países, avançados e em desenvolvimento, trabalha para adaptar sua indústria, serviços e agricultura às novas tecnologias que prenunciam mudanças profundas na forma de organização da sociedade, o Brasil se debate para sair da recessão, superar as dificuldades fiscais e o constrangimento gerado por escândalos de corrupção em série. A quase-paralisia do corpo de governo, cujo comando apenas opera pela sua própria sobrevivência, oferece para a sociedade, mais uma vez, o curto prazo como a salvação.

No ponto de partida deste ensaio está a busca das trajetórias de longa duração. Temos consciência que as dificuldades são enormes em tempos de regressão democrática e social. Mas não há outro caminho para a reflexão a não ser retirar a Educação, Ciência, Tecnologia e Inovação (CT\&I) da agenda do esquecimento a que foram condenadas.

Estratégias de Tecnologia e Inovação não suportam interrupções, porque a instabilidade envelhece seus resultados e drena seu ímpeto. São atividades intensivas em conhecimento, fruto de redes que não respeitam fronteiras e que possuem temporalidade própria. Não são criaturas de gabinete nem de livros-texto, mas são construídas como bens públicos, que nascem do diálogo na sociedade. Por isso vivem da experimentação, da tentativa e do erro.

As nações que conseguem se organizar para constantemente buscar respostas para os problemas da sociedade - como a pobreza, as desigualdades e a qualidade de vida de sua população - são mais justas e civilizadas.

Mas, para isso, precisam de estratégias de longo prazo, que equacionem o baixo crescimento e suas relações com tecnologia e inovação. Sem isso, todo esforço será inócuo, pois o desenvolvimento torna-se fugaz ou mesmo ilusório sem o aumento constante da produtividade, que tem na inovação e na tecnologia um de seus suportes fundamentais.

Em tempos espinhosos, a responsabilidade pública tende a se diluir em meio à crise fiscal que promove retração do Estado e de suas iniciativas. Exatamente por isso, tecnologia e inovação são tratadas, mais uma vez, como subproduto do funcionamento da economia, cujo desenvolvimento adviria naturalmente do crescimento. A questão de fundo é que não há novidade alguma nessa 
abordagem. Pelo contrário, apenas representa a reedição de omissões recorrentes na trajetória brasileira. E respondem por boa parcela de responsabilidade pela perda de oportunidades históricas e pela nossa participação apenas marginal nas principais ondas tecnológicas que mudaram a face do mundo desde a Segunda Guerra Mundial.

Se queremos encontrar caminhos para um crescimento econômico, capaz de gerar emprego e renda, que seja sustentável e inclusivo, o primeiro passo é reconhecer que a economia brasileira vive, estruturalmente, uma compressão em seus índices de produtividade, em especial os da indústria, o que a torna mais vulnerável e menos competitiva internacionalmente, com todas as implicações adversas para o crescimento e a geração de empregos de qualidade.

Abordaremos cinco pontos neste trabalho: (i) o calcanhar de Aquiles da produtividade e a fragilidade da indústria; (ii) inovação no Brasil; (iii) o novo ciclo tecnológico; (iv) o que há de novo no mundo digital; (v) algumas respostas; (vi) como mudar para recuperar parte do tempo perdido.

\section{Produtividade e indústria na raiz do crescimento}

Sabe-se que tecnologia e inovação não constituem panaceia. Mas são ativos estratégicos que podem impulsionar e sustentar o crescimento, além de se mostrarem determinantes para potencializar a velocidade de recuperação em tempos de crise (OECD, 2009).

No ambiente corrosivo que vive o país, o debate sobre prioridades e alocação dos esparsos recursos disponíveis exige a ampliação da sintonia entre a agenda econômica e as prioridades nacionais. Nessa linha, os esforços para estancar a contração da economia devem incluir mais do que o necessário ajuste fiscal; é fundamental se balizar por políticas de médio e longo prazo voltadas para equacionar os problemas que drenam dinamismo da economia, a começar pela baixa produtividade brasileira.

É sempre bom lembrar que no Brasil a produtividade está praticamente estagnada desde o final da década de 1970, ou seja, mesmo após ter passado pelo crivo de diferentes governos.

Os dados encontrados por pesquisadores do Ipea, que abordaram a trajetória da produtividade com distintas metodologias (Gráfico 1), ajudam a compreender as dificuldades de uma economia para atender a demanda sem inflação, que perde espaço no comércio internacional e que responde apenas por espasmos aos estímulos de crescimento. A situação do Brasil torna-se ainda mais grave quando comparada à trajetória de outros países, desenvolvidos e emergentes.

Até mesmo o desempenho positivo da produtividade nos anos $2000 \mathrm{se}$ deu sustentado pelo aumento da força de trabalho ocupada, ou seja, por uma maior participação de trabalhadores no mercado de trabalho, e não por melhoria nos indicadores de produtividade. 


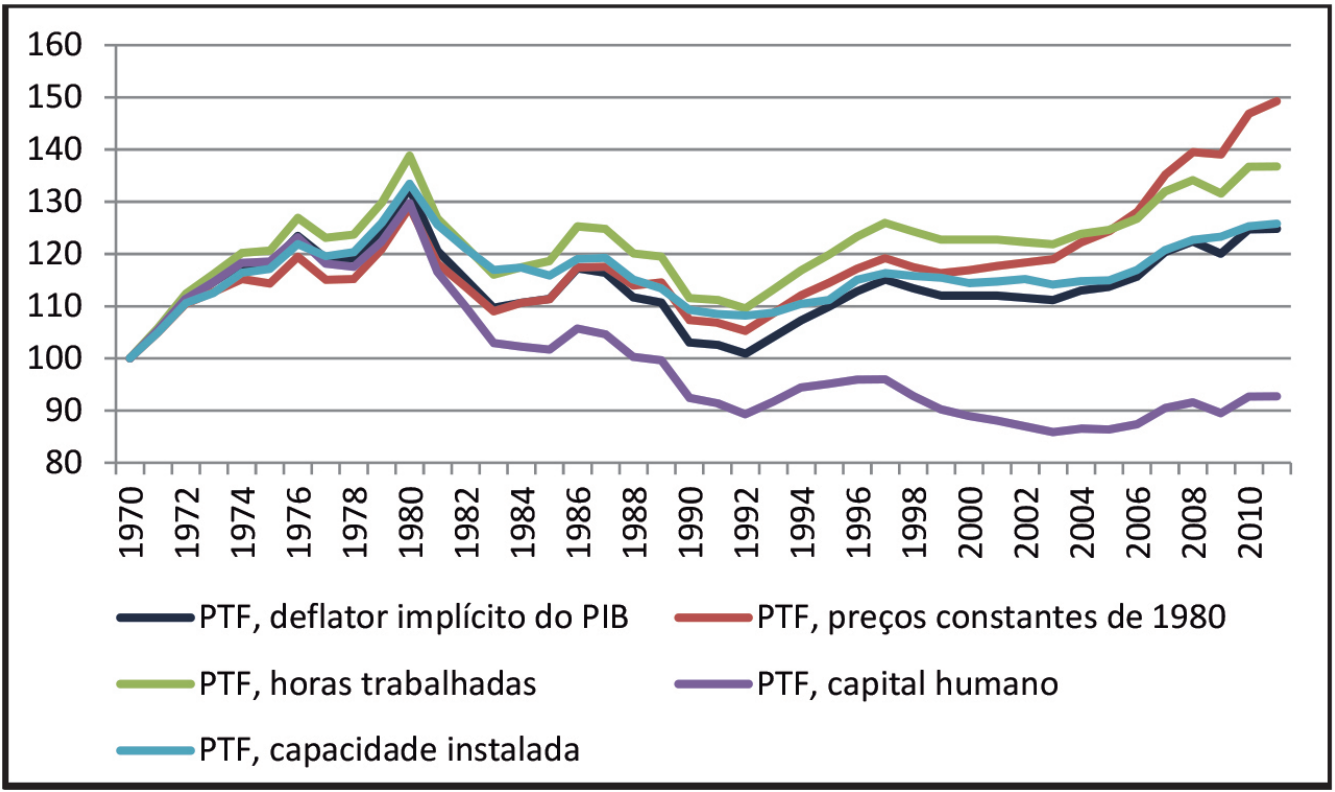

Fonte: Ellery, R. (capítulo 2) in De Negri e Cavalcante (2014).

Gráfico 1 - Diferentes medidas para a produtividade total dos fatores

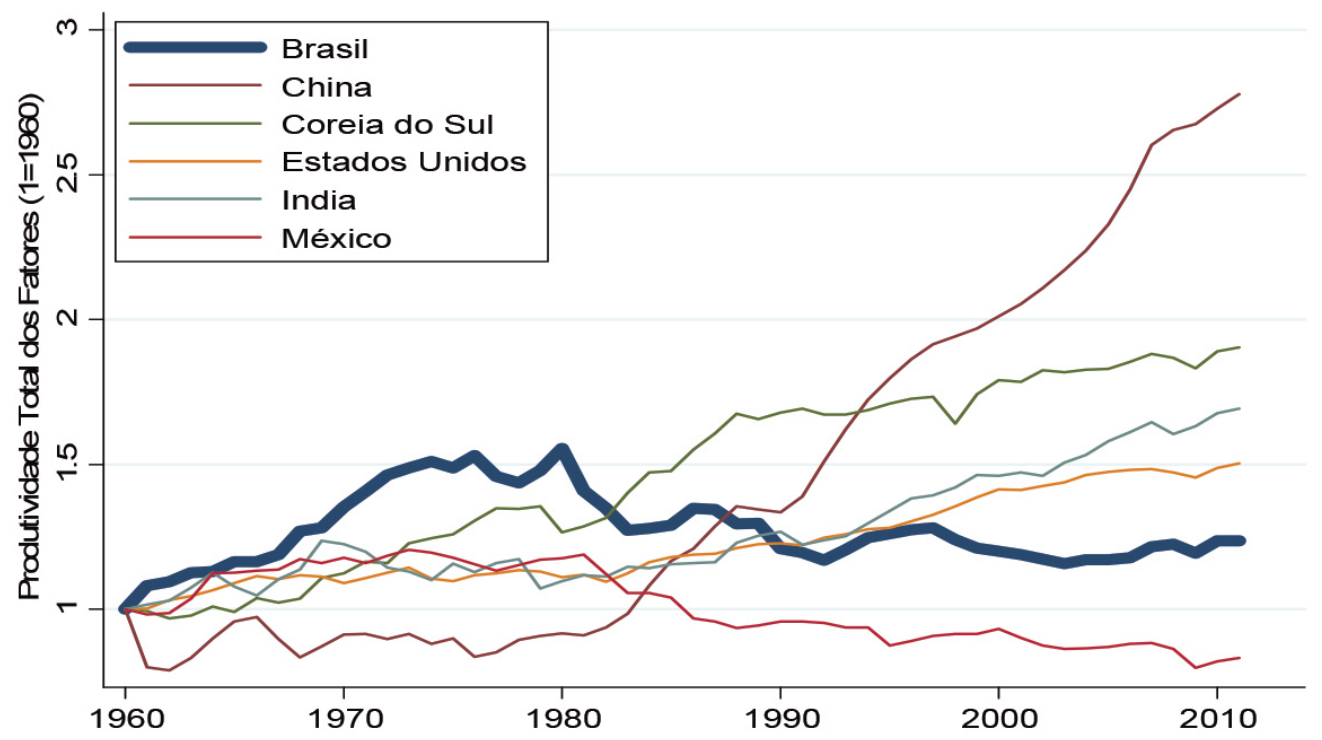

Fonte: Mation (cap. 6) in De Negri e Cavalcanti (2014).

Gráfico 2 - Evolução da Produtividade em vários países

Os dados mostram ainda que a economia brasileira vive uma retração drástica do seu motor historicamente mais importante, a indústria (De Negri; Cavalcante, 2014). As consequências remetem à perda de dinamismo do conjunto da economia. E, do ponto de vista social, a uma retração profunda do emprego, em especial do emprego de qualidade, como indicam os dois gráficos a seguir. 


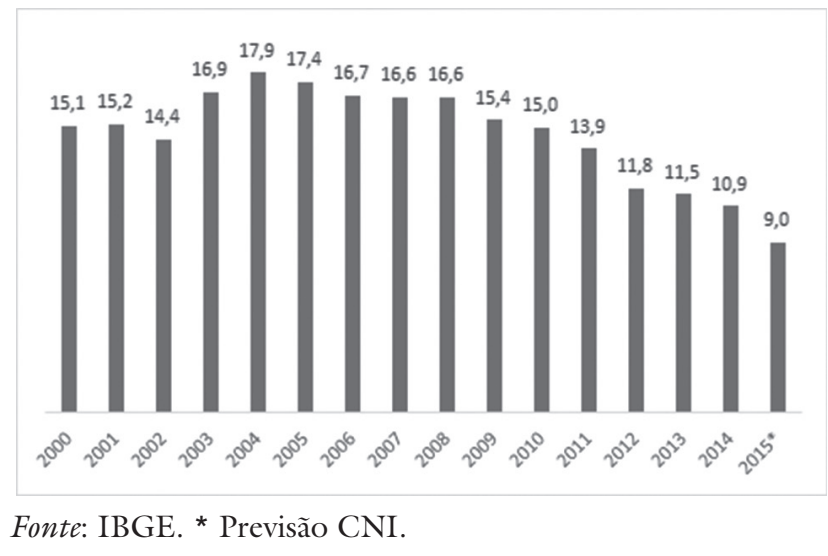

Gráfico 3 - Participação da Indústria de Transformação no PIB, 2000-2015 (\%)

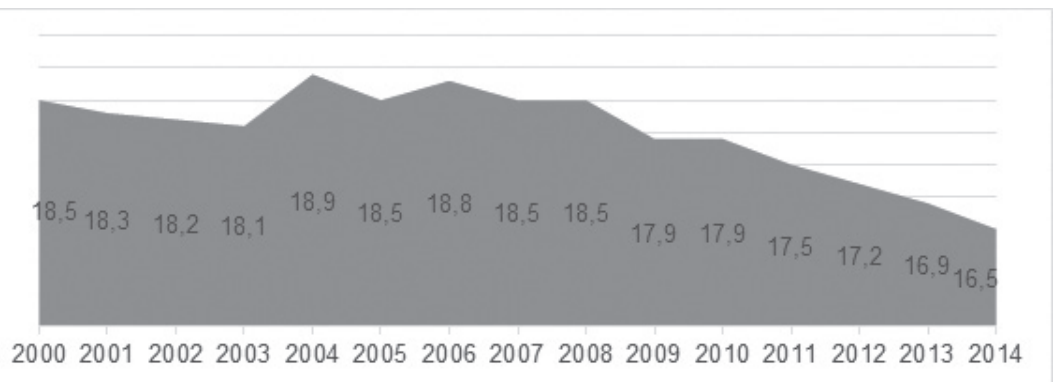

Fonte: RAIS.

Gráfico 4 - Participação da Indústria no Emprego - 2000-2014 (\%)

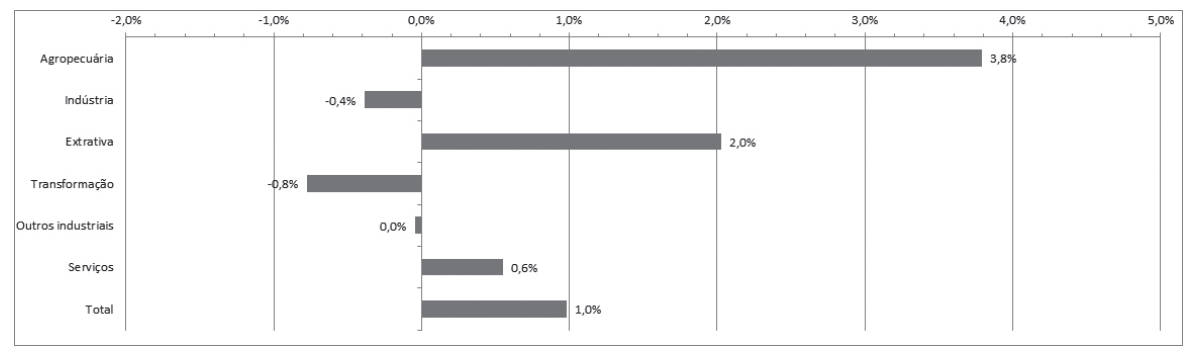

Fonte: Cavalcanti e De Negri (cap.5); Squeff e De Negri (cap.8). (in De Negri; Cavalcanti, 2014). Gráfico 5 - Produtividade do Trabalho - 2000-2009 - Crescimento Médio Anual

A comparação da produtividade entre os setores no país realça a fragilidade da indústria brasileira: entre 2000 e 2009 , enquanto a agropecuária, a indústria extrativa e os serviços melhoraram sua produtividade, a indústria de transformação acumulou contração de quase 1\%, reforçando sua fragilidade competitiva. 
Os caminhos para se quebrar a sequência viciosa nem sempre são claros, uma vez que os estudos sobre o que deflagra a recuperação e o que sustenta o crescimento não são conclusivos sobre seus determinantes. Décadas de estagnação, porém, permitiram a identificação de dimensões subestimadas ao longo do tempo, principalmente por conta das dificuldades de seu encaixe na modelagem que orienta o discurso econômico predominante.

Produtividade ganha maior sentido quando conectada ao trabalho mais inteligente, ou seja, mais carregado de conhecimento. É somente o aprimoramento das habilidades de quem trabalha que gera uma combinação ponderada entre ideias, tecnologia, modelos avançados de produção e as pessoas. Esses processos interativos que capacitam o conhecimento a movimentar as engrenagens da economia atendem pelo nome de inovação. E é precisamente a capacidade das economias de incorporar, adaptar e produzir inovações de modo ininterrupto que viabiliza ganhos crescentes de eficiência na atividade econômica. Não é por acaso que a economia brasileira é permanentemente punida pela fragilidade dessas dinâmicas.

Nesse sentido, a elevação do patamar de Pesquisa e Desenvolvimento (P\&D) das empresas, assim como a busca persistente na diminuição da distância que separa o Brasil das economias que atuam na fronteira do conhecimento são os únicos caminhos que levam à reversão da longa trajetória de baixo desempenho. Sem esse esforço, que exige cooperação entre o setor público e privado, não haverá alteração profunda da estrutura produtiva, condição para sustentar ciclos prolongados de elevação da produtividade. Tampouco haverá a formação de uma cultura orientada para a inovação, e que penetre em todos os poros da atividade econômica.

Economias mais abertas saem com vantagens nessa corrida pela competitividade. Isso porque o crescimento de longa duração, além de se beneficiar de um ambiente de estabilidade econômica e regras claras, o que, em princípio, aumenta a previsibilidade e estimula ao investimento, depende da demanda e da qualidade da oferta, o que significa, antes de tudo, aumento constante da capacidade de trabalho, melhoria dos fatores de produção e elevação da produtividade a partir da absorção e geração de tecnologias e inovações. Desse ponto de vista, economias mais abertas à concorrência, circulação de bens, conhecimento e tecnologias estão mais bem posicionadas para impulsar dinâmicas mais inovadoras.

O Brasil fez várias tentativas para caminhar nessa direção. Mas desde o esgotamento do ciclo de crescimento acelerado, que minguou no final dos anos 1970, o país tateia em busca de novos caminhos para o desenvolvimento, quase sempre com custos econômicos e sociais enormes.

O diagnóstico corrente, ainda que trate de questões importantes, nem sempre surge como novidade: obstáculos na frágil estrutura educacional - que avança lentamente e permanece distante dos padrões razoáveis de qualidade -, na infraestrutura, no financiamento de médio e longo prazos, no sistema regu- 
latório e tributário. Certamente todos esses itens dificultaram muito o crescimento constante da economia e a dinamização da atividade empresarial e dos mercados.

Mas há uma questão de fundo, porém, que diz respeito ao baixo desempenho da nossa economia e que toca nas dificuldades que vivem as empresas para aumentar sua eficiência. Gestão é essencial nesse debate, mas de alcance circunstancial e restrito. Num horizonte mais amplo, é possível enxergar que, há quase quarenta anos, a economia brasileira e suas empresas continuam se debatendo para completar o trânsito de uma economia fechada e protegida - que marcou o período nacional-desenvolvimentista - para uma economia aberta e competitiva.

Nos anos 1990 e início dos anos 2000, difundiu-se a crença de que a abertura e a liberalização da economia seriam suficientes para gerar saltos de produtividade e desenvolvimento tecnológico. Em vão. Nos anos 2000, a busca de um novo equilíbrio entre atuação do Estado em sinergia com os mercados chegou a apontar, por breves momentos, rumos mais consistentes para o país. As medidas de fôlego que permitiriam mudanças institucionais profundas foram apenas esboçadas, ou moldadas de forma incompleta ou, simplesmente, foram abandonadas. A tradição de confinamento e a orientação para o mercado interno que marcaram desde o nascimento a maior parte do empresariado brasileiro ajudam a explicar a perda de oportunidades abertas para viabilizar mudanças de fundo na estrutura produtiva, no mercado de trabalho, na infraestrutura, no sistema de financiamento e na arquitetura política. Apesar dos avanços pontuais, que tornaram o ambiente interno um pouco mais favorável à inovação nas empresas, o fato é que o Brasil, mais uma vez, estacionou no meio do caminho, sem conseguir elevar seu patamar de competitividade.

\section{Inovação e tecnologia}

A posição do Brasil é intermediária no concerto das nações, nem muito atrasado nem muito avançado. Se é certo que os passos dados nos últimos trinta anos foram significativos para tecnologia e inovação, também é certo que a crise atual, marcada pelo abandono de toda e qualquer estratégia ligada à educação, ciência e tecnologia, é responsável pelo aumento da distância - que já era grande - que separa o país das nações que conseguem ter algum protagonismo no cenário internacional.

Por isso mesmo, o esforço pela educação e pela elevação do patamar de Pesquisa e Desenvolvimento (P\&D) das empresas e a busca obstinada da diminuição do gap que separa nossa economia da dos países que produzem na fronteira do conhecimento são os únicos caminhos que levam à reversão da trajetória de baixo desempenho.

Entre 2000 e 2014, os dispêndios em P\&D no Brasil quase dobraram: de $\mathrm{R} \$ 38,4$ bilhões passaram a $\mathrm{R} \$ 73,6$ bilhões (em valores de 2014). Mas para acompanhar o esforço que a China fez, por exemplo, o crescimento real teria que ser no mínimo o dobro do realizado. Esse crescimento foi mais intenso nos 
gastos do governo federal (113\%) e menor nos do setor empresarial (87\%) e dos governos estaduais $(69 \%) .{ }^{1}$ Em termos relativos, considerando-se os dispêndios em P\&D em relação ao PIB, foi observado um crescimento real de $17 \%$ no período, passando de 1,04\% para 1,27\% do PIB, entre os anos de 2000 e 2013 (MCTIC, 2017). Para um país das dimensões do Brasil, seria necessário que os investimentos em P\&D atingissem no mínimo $2 \%$ como proporção do PIB no final desta década (anos 2010), o que dificilmente ocorrerá.

Apesar de dotado de um arcabouço institucional relativamente moderno quando comparado às melhores práticas mundiais, o investimento em P\&D no Brasil, como proporção do PIB, não mudou de patamar na última década. $\mathrm{O}$ Gráfico 6 mostra que o país continua muito distante da fronteira de investimento em P\&D no mundo e não há uma tendência de convergência desses investimentos, principalmente quando comparados aos esforços de países como Estados Unidos e Alemanha. O quadro brasileiro se reproduz, apesar de diferenças, em praticamente todos os países em desenvolvimento. Os exemplos internacionais mostram que esse quadro pode ser alterado de forma significativa com a adoção de medidas de forte impacto pelo setor público e pelo setor privado. As experiências como as da Coreia do Sul e da China registram pontos de inflexão importantes no seu esforço de investimento em P\&D desde os anos 2000, cujos resultados permitiram reverter, ainda que parcialmente, a tendência de seu histórico afastamento da fronteira mundial.

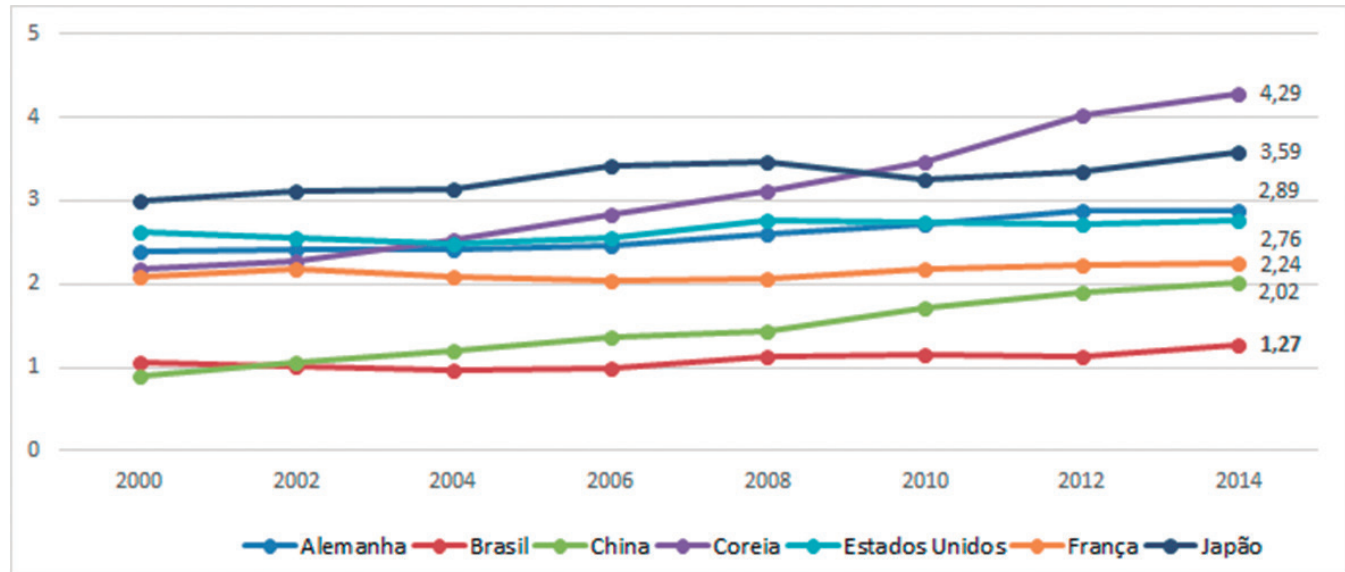

Fonte: MCTIC, OECD. Elaboração dos autores.

Gráfico 6 - Dispêndios em P\&D em relação ao PIB - 2000-2014 (\%)

No que tange à produção científica nacional, na última década o crescimento foi extremamente significativo. Em números absolutos, entre 2000 e 2015, o número de artigos de pesquisadores brasileiros publicados em periódicos indexados internacionalmente quadruplicou (passando de 14.247 para 63.126 artigos, segundo dados da Scopus). Como resultado dessa expansão, a participação do Brasil na produção de artigos passou de 1,18\% para 2,57\% da produção 
mundial. Em número de citações, porém, o país ainda precisa avançar, pois o impacto da produção tem evoluído de forma menos proeminente (Chaimovich, 2016; MCTIC, 2017 ).

No que se refere aos pedidos de patentes, a evolução foi menos expressiva. Num período de 16 anos, os pedidos de patente apresentados ao Instituto Nacional de Propriedade Intelectual (Inpi) passaram de 20.854 em 2000, para 23.152 em 2006 e para $31.020 \mathrm{em} 2016$ (MCTIC, 2017 ). O crescimento de cerca de $50 \%$ nesse intervalo foi muito inferior ao registrado na produção científica. O depósito feito por residentes no país teve desempenho ainda pior, com aumento aproximado de $25 \%$ (de 6.449 para 8.082 ), muito inferior ao avanço da produção científica.

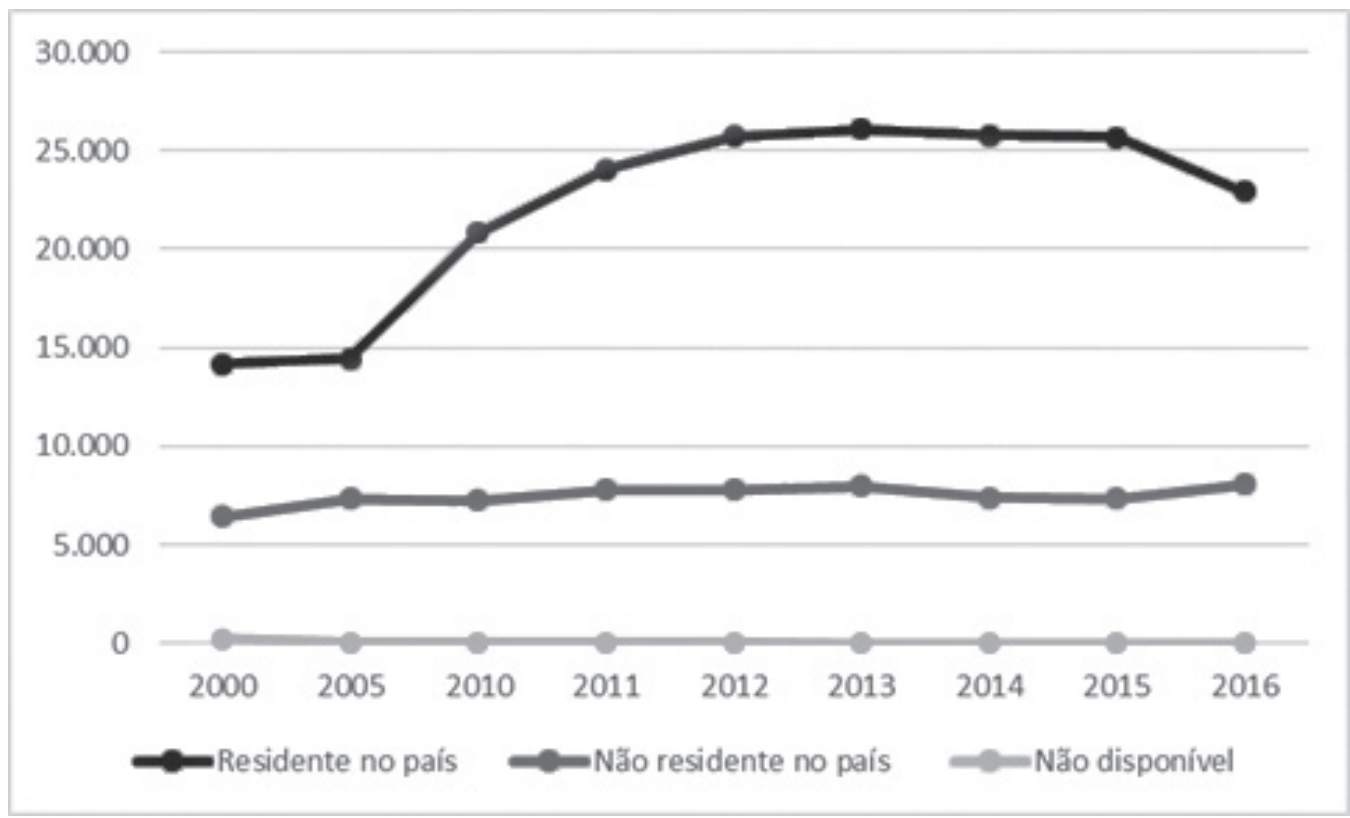

Fonte: MCTIC. Elaboração dos autores.

Nota: Não avaliados por não identificação do primeiro depositante ou da origem do primeiro depositante. Dados preliminares para 2013 a 2016.

Gráfico 7 - Pedidos de patentes depositados no INPI (por origem do depositante) $-2000-2013$

Deve ser ressaltado que em 2008 o Brasil ultrapassou 160 publicações por 1 milhão de habitantes. De acordo com a base Web Of Science, esse é um indicativo relevante da massa crítica necessária para o desenvolvimento científico e tecnológico. Esse limiar é, entretanto, móvel e crescente no mundo. No caso do Brasil, ainda permanece forte desconexão entre a produção científica e a tecnológica. Na China, por exemplo, o número de pedidos de patentes teve crescimento percentual maior que o da publicação de artigos no período de 1996 a 2012. 
Ainda que modesto diante de outras economias, esse conjunto de esforços corre o risco de se perder, caso o cenário de encolhimento de recursos observado nos últimos anos seja mantido.

Um panorama sobre os investimentos mostra que houve crescimento acelerado dos recursos do MCTIC entre 2000 e 2010 e a entrada de novos personagens no mundo da pesquisa científica e tecnológica (como os Ministérios da Defesa, da Agricultura, da Educação e da Saúde, dentre outros), ainda que o conjunto do sistema operasse muito abaixo do necessário e sem estabilidade. Contudo, desde 2014 os recursos viveram trajetória de queda. No princípio, lenta e gradual. Em 2016 e 2017 tornaram-se dramáticas, ameaçando o funcionamento básico de todo o sistema de CT\&I. ${ }^{2}$ Projeções iniciais de alguns analistas indicam que em 2017 o investimento em P\&D como proporção do PIB poderá retornar para o início dos anos 2000, exatamente no período em que um novo ciclo tecnológico começou a sacodir os países avançados e promete submergir os emergentes, se insistirem em permanecer no atraso.

A escolha brasileira, portanto, em não priorizar os investimento em pesquisa, desenvolvimento e inovação (PD\&I), se de um lado põe em risco trajetórias de conhecimento construídas, com muito esforço, nos últimos anos, de outro significa que o país navega na contramão da estratégia adotada por diversas outras economias, que investem mais em tecnologia a fim de manter ou conquistar protagonismo internacional, sobretudo nesse momento de transição para uma nova economia, que promete derrubar ainda mais os custos de produção.

\section{A nova onda tecnológica}

A crise internacional de 2008 está na raiz de uma nova onda de políticas e de programas de inovação que tomou corpo entre países avançados e em desenvolvimento. O Plano para o Crescimento do Reino Unido (2009), o Ato de Recuperação e Reinvestimento e o Made in América nos Estados Unidos (2009), a estruturação de uma nova política industrial para o Japão (2010), o Fundo de Investimento Estratégico da França (2011) e o Plano para o Desenvolvimento da Ciência e Tecnologia da China (2011) são alguns exemplos de como governos com orientações muito diferenciadas reagiram diante da queda do dinamismo de suas economias e procuraram redefinir instrumentos e revisar seus marcos legais para elevar a competitividade de suas economias. O Brasil também participou desse movimento com os planos Brasil Maior (2011), e o Inova Empresa (2013), embora nem sempre com o mesmo foco e objetivos.

Apesar das características contracíclicas dessa onda, os programas mais consistentes, em curso nos países avançados e em alguns emergentes, voltam-se para uma reconfiguração dos sistemas produtivos, impulsionada por avanços tecnológicos que prenunciam alterações profundas na indústria, agricultura, comércio e serviços.

Não à toa, a nova geração de políticas públicas tem como alvo o estímulo à Pesquisa e Desenvolvimento (P\&D) nas empresas como instrumento de eleva- 
ção da produtividade. O contraste, assim, torna-se grande quando a comparação é feita com as tradicionais políticas industriais que reeditaram à exaustão velhos instrumentos de subsídio e proteção, de alto custo fiscal. As políticas avançadas de hoje, além do foco claro em inovação, adquirem sentido apenas quando buscam claramente a elevação do padrão produtivo da economia, em especial da indústria. Assim fazendo, expõem as empresas ineficientes e mais defasadas à competição e abrem caminho para a oxigenação da economia com o surgimento de novas empresas.

Nessa equação, a indústria ocupa lugar especial, mesmo declinante. Mas não uma indústria qualquer.

Ao observar os dados sobre a queda na participação da indústria na composição do PIB nas economias em quase todo o mundo, o debate sobre eventual desindustrialização (Rodrik, 2016; Grabowski, 2017) surge quase que naturalmente. Com maior gravidade entre os emergentes, mas também entre os países desenvolvidos. O debate, dadas as mudanças nas características da competição global, vai muito além da tradicional relação de causalidade, expressa na relação entre crescimento dos serviços e declínio industrial.

Nas economias avançadas, a diminuição do peso relativo da indústria surgiu, de início, vinculada à drenagem de competências e especialidades em segmentos mais tradicionais, dadas as estratégias de outsourcing intensamente utilizadas pelas empresas e consequente migração de plantas produtivas para países emergentes, em especial a China.

Esse debate é fundamental tanto para as economias puxadas pela inovação, como é o caso dos países desenvolvidos, quanto para os emergentes, como o Brasil, pelo impacto que as estratégias globais provocam. Estudos mostram que desde os anos 2000 a migração contemporânea não se restringiu somente à produção de bens de baixo valor agregado, mas incorporou setores de engenharia sofisticada que alterou a capacidade de fabricação industrial em países como Estados Unidos, Canadá, Reino Unido, França e mesmo Alemanha. A perda de componentes necessários para a produção de bens de maior complexidade, como o "conhecimento, pessoal qualificado e infraestrutura de suprimentos" (Pisano; Shih, 2009, p.3) foi sentida na mudança de domicílio industrial da produção de computadores, displays de alta resolução, materiais avançados para a indústria aeronáutica, semicondutores, diodos e sensores, para citar alguns, que passaram a ser gradativamente produzidos, planejados e concebidos em países asiáticos.

Essa nova cartografia industrial abriu vazios na capacidade de manufatura dos países desenvolvidos e desorganizou, ainda que parcialmente, a intrincada malha de fornecedores e cadeias produtivas construídas ao longo de décadas.

Pesquisas recentes ampliaram ainda mais esse debate e sugeriram que a perda de capacidade industrial das economias mais maduras estaria vinculada não somente à migração de empresas para países emergentes, mas também ao 
trânsito mais fácil e flexível da mão de obra e de competências produtivas entre as áreas e setores da economia (Grabowski, 2017; Guajardo; Molano; Sica, 2016). Em outras palavras, as fronteiras entre esses domínios haviam se tornado fluidas, indústria e serviços estariam cada vez mais integrados e, assim, apontavam para a formação de novos fundamentos para o mundo industrial.

A Industrie 4.0, ${ }^{3}$ segundo a vertente alemã, e a Advanced Manufacturing (como denominam os americanos) ${ }^{4}$ seriam expressões dessa nova síntese entre homens, máquinas e inteligência de software, capaz de abrir um novo capítulo na trajetória das revoluções industriais. ${ }^{5}$

Ao observar esse movimento, percebe-se que:

- Esses processos se apoiam no aprofundamento da interdependência produtiva na indústria mundial, com a diversificação da origem do valor adicionado no fluxo geral de mercadorias e mesmo de serviços (Gereffi, 2014);

- A participação e o fortalecimento das relações de cada indústria doméstica com cadeias globais de valor passaram a ser peça-chave nas políticas de inovação, por facilitarem o fluxo de conhecimento, a capacitação, elevação de padrões de qualidade e o aprendizado (Gereffi; Lee, 2012; Lema; Quadros; Schmitz, 2015);

- O amplo movimento de internacionalização da produção e dos serviços também alterou padrões de competição de alcance limitado às economias nacionais e questionou estratégias institucionais, como nas universidades, empurrando-as para a internacionalização de suas atividades;

- A nova manufatura passou a emitir fortes sinais no sentido de que a geração de emprego não está entre suas características mais substantivas (Brynjolfsson; McAfee, 2012; Acemoglu; Restrepo, 2016);

- Apesar dos sinais negativos quanto à sua capacidade criadora de emprego, a indústria ainda ocupa lugar especial e se constitui como peça essencial para manter a capacidade de adaptação das economias e o dinamismo dos sistemas de inovação (Pisano; Shih, 2012, cap.5; Pisano, 2015).

Exatamente pela importância da indústria nos processos que oxigenam o conjunto da economia, os países mais desenvolvidos aumentaram o peso específico dos processos de inovação, tanto para o enfrentamento da crise quanto para manutenção do bem-estar social. Incorporaram em suas estratégias que o desenvolvimento de inovações e de tecnologia é chave para o aumento da produtividade e que, por isso, os investimentos públicos orientados para esse fim devem ser preservados ou elevados de modo a contrabalançar a queda no investimento privado (OCDE, 2015), mesmo diante do encolhimento adverso das finanças públicas.

Essa estratégia foi adotada no passado recente por países como Finlândia, Suécia, Coreia e Taiwan, assim como orienta atualmente as políticas públicas na China, nos Estados Unidos, Japão, França e Alemanha, para citar alguns. Esse esforço adquire maior significado quando se reconhece que o ritmo da econo- 
mia mundial é de quase estagnação, em que os cenários mais otimistas indicam um moderado crescimento mundial, puxado em grande parte pelas nações avançadas (World Bank, 2016).

Países como Estados Unidos e Alemanha investem prioritariamente nessas tecnologias, buscando redução de custos e do tempo de produção, menor consumo de energia, maior segurança aos trabalhadores, entre outros benefícios. Trata-se de novas modalidades de organização da produção, que elevam a qualidade e a eficiência da indústria, extrapolam o mundo fabril e apontam para novas dimensões de consumo, de cultura e de sociabilidade. O Brasil, que já perdeu o bonde da microeletrônica e das tecnologias de informação e comunicação, não deve fechar os olhos para essas novas tendências. Não por qualquer modismo, mas pela necessidade de promover uma reviravolta em seu sistema produtivo.

Por conta das implicações profundas para as economias, empresas, negócios e para a qualidade de vida de suas populações, muitos governos tomaram a iniciativa de formular uma nova geração de políticas e programas de inovação e de tecnologia (Andrews; Criscuolo; Gal, 2015; OECD, 2015; Jorgenson; Ho; Samuels, 2016. Buscam, com isso, sintonizar suas economias com as novas realidades tecnológicas e, assim, manter a competitividade de suas empresas e suas posições no comércio internacional.

Para os países emergentes, é essencial reconhecer que a velocidade das mudanças, as iniciativas de um pequeno número de países, empresas e universidades que dominam essas novas tecnologias, assim como o enorme volume de recursos envolvido colocam desafios enormes. De um lado, os avanços tendem a aumentar o gap, que já é grande, que separa suas economias dos países avançados. De outro, as inovações em curso abrem novas oportunidades de desenvolvimento. Mas exigem senso de urgência e postura proativa para dar vida a uma grande articulação entre o setor público e o privado, capaz de mobilizar universidades, empresas e instituições de governo para disseminar, absorver, testar, implementar e gerar novas tecnologias.

\section{Digitalizar, integrar, automatizar}

Para além de um mosaico de tecnologias de última geração, que permeia a eletrônica, a informatização de processos, inteligência artificial, robótica avançada, novos materiais e fontes de energia, está em curso a formação de um complexo de tecnologias que oferecem as bases para a emergência de novas indústrias.

A nova conectividade entre equipamentos, pessoas e a automação generalizada coloca em xeque as estruturas industriais existentes e, de modo mais enfático, as mais envelhecidas como as existentes no Brasil. Ao mesmo tempo, abrem novas oportunidades para as empresas, para a economia e para os países, uma vez que são capazes de gerar processos digitais avançados e de viabilizar integração produtiva com ganhos enormes de produtividade e eficiência.

Em um sentido amplo, a manufatura tradicional consiste na fabricação e montagem de produtos via processos, em geral, lineares. Na manufatura avançada: 
- Os novos materiais tendem a se apresentar como parte integrante dos processos de fabricação;

As fronteiras entre fabricação e montagem praticamente tendem se apagar quando tratadas por processos intensivos de automação;

- Os produtos deixariam de ser apenas artefatos físicos, mas tenderiam a compor soluções completas, capazes de combinar o produto físico com software e serviços;

- Processos sofisticados de reaproveitamento de rejeitos industriais indicam dimensões inexploradas à reciclagem, prolongando o ciclo de vida e a otimização dos produtos, sem se esgotar em precauções ecológicas ou ambientais.

Como primeira aproximação, pode-se compreender a manufatura avançada como um corpo de soluções integradas, que combinam a produção de artefatos físicos com software e serviços, baseadas na reciclagem intensiva de materiais e em processos de fabricação e de consumo de supereficiente de energia.

Figura l - Expansão e superação da manufatura do século XX

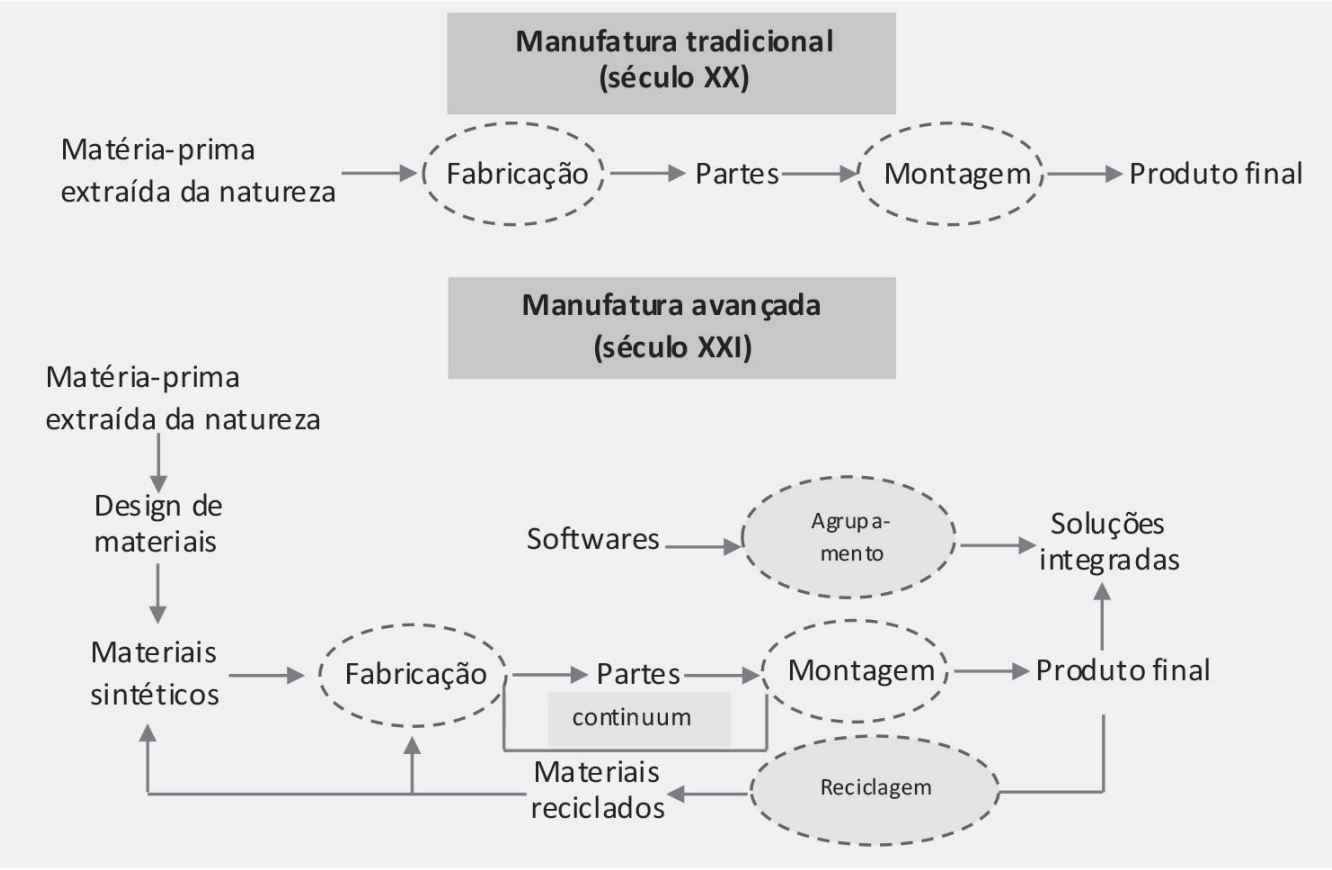

Fonte: Adaptado pelos autores. Locke \& Wellhausen, 2014, p.254.

Como grandes áreas nucleadoras, sugerimos tentativamente os seguintes conjuntos:

- Nanoengenharia de materiais: produção em grafeno, roll-to-roll manufacturing, impressão de semicondutores em 3D, fibras e compósitos;

- Manufatura de precisão: impressão residencial em 3D, prototipagem 
integrada à computação e design, máquinas elétricas, foundry, laser-based manufacturing;

- Robótica e automação: automação inteligente, sensores, robôs flexíveis, colaboração homem-robô, sensoriamento remoto e telerobótica;

- Design e gestão de cadeias: design of complex systems, cloud computing para Cad/Cam;

- Fontes de energia: fotovoltaica e energia solar para manufatura, armazenamento, reciclagem;

- Nova geração de eletrônicos: nanolitografia e ultravioleta, computer interfaces, wireless manufacturing;

- Biomanufacturing: biofármacos: stem cell-based manufacturing, engenharia de órgãos humanos, medicina personalizada, terapias regenerativas;

- Inteligência artificial: big data, internet das coisas (IoT), cloud computing, quantum computing.

Em linguagem mais precisa, dado seu potencial multiplicador, essas tecnologias são tratadas como key enabling technologies. Fortemente integradoras, tendem a se articular como um tripé, marcado por três macropilares de sustentação: digitalização, integração e automação.

Em que pese o grande desenho de futuro que suscitam, é oportuno registrar que essas tecnologias se referem a indústrias ainda muito incipientes; algumas são apenas tendências e outras são pontos longínquos.

Para aumentar ainda mais a precisão sobre o estágio de seu desenvolvimento, é importante estabelecer que todas essas tecnologias integram o repertório de experimentação de um pequeno grupo de países, que conta com um número ainda menor de centros e empresas aptas a desenvolvê-las. Isso significa que, de modo geral, essas tecnologias nascentes ainda são inacessíveis para grande parte dos países emergentes, o que inclui até mesmo as subsidiárias de multinacionais.

Essas considerações sobre o caráter ainda exploratório das novas tecnologias não oferecem nenhum conforto aos países em desenvolvimento. A rapidez de sua evolução e a explosão de novas aplicações e vertentes de uso não deixam dúvidas sobre a presteza de sua disseminação global e, mais ainda, sobre o forte impacto que deverá provocar nos países mais atrasados. Alguns, positivos, pois certamente ajudarão a dinamizar e a elevar a eficiência de economias como a brasileira. Mas, há outros que devem servir de alerta, como a redução do emprego e a possibilidade de empurrar o conjunto da indústria para as margens economia mundial. No que se refere ao emprego, é certo que os sinais ainda são inconclusivos, apesar de robustas indicações, como as apresentadas nas pesquisas recentes de Acemoglu e Restrepo (2016).

Sobre o segundo alerta, apesar do risco real, muito está nas mãos do Brasil e da sua capacidade de trabalhar com senso de urgência e disposição efetiva para participar, ainda que minimamente, desse novo ciclo. 


\section{Respostas que inspiram}

O rastreamento de algumas experiências internacionais pode ajudar nossa reflexão.

Na primeira metade dos anos 1990, a Finlândia mergulhou em profunda recessão. Em um intervalo de apenas quatro anos, a produção encolheu $10 \%$ e o desemprego quadruplicou, atingindo mais de $15 \%$ da força de trabalho (OECD, 2009). Para superar as dificuldades da economia, o governo combinou medidas tradicionais - como aumento de impostos e corte de gastos para viabilizar o ajuste fiscal - com o incremento do investimento em P\&D, assim como em educação e infraestrutura. O resultado alcançado foi a duplicação do número de ingressantes no ensino superior e a multiplicação por quatro do número de novos alunos nas escolas politécnicas.

Essa agenda, cuidadosamente discutida com a sociedade, permitiu ao país sair da crise com uma economia maior e mais forte do que antes, com uma atividade mais complexa e diversificada, muito mais intensiva em tecnologia e conhecimento do que no período pré-crise. Na Finlândia, o destaque para as tecnologias de informação e comunicação deu novo dinamismo e elevou a competitividade de todo o país, como registrado no ranking elaborado pelo Fórum Econômico Mundial em 2005 e 2006 (Arbix; Varon, 2009).

A experiência coreana também demonstra como uma boa gestão de períodos adversos pode acelerar ajustes estruturais (OECD, 2009). A crise que atingiu a Coreia do Sul no final dos anos 1990 causou queda no emprego de profissionais qualificados e nos investimentos privados em P\&D. Como ocorrera na Finlândia, a resposta do governo foi no sentido de investir em pesquisa, tecnologia e educação. Foram adotadas também medidas para fomentar o desenvolvimento de pequenas e médias empresas (PME) de base tecnológica, tais como melhorias no ambiente regulatório, incentivos fiscais e fundos de apoio à P\&D. Essas medidas contribuíram para um aumento exponencial das startups e para dobrar a participação das mesmas nos gastos privados em P\&D, de $12 \% \mathrm{em}$ 1997 para $24 \%$ em 2006.

A trajetória da China nos últimos 15 anos também exibe uma política de CT\&I bastante vigorosa. Ilustrativo disso é que, em 2000, o investimento em P\&D foi da ordem de US\$ 33 bilhões (valores correntes) e saltou para mais de US\$ 368 bilhões em 2014. Como proporção do PIB, significa que o volume gasto duplicou - de $0,9 \%$ para $2 \%$ (meta que já constava na estratégia nacional de CT\&I chinesa para 2010). Consequentemente, a China superou o Japão e os 28 países da União Europeia em montante investido em P\&D, ficando atrás apenas dos Estados Unidos. Mesmo considerando a desaceleração dos investimentos após 2008, os gastos continuaram em expansão e mais que dobraram na comparação 2008-2014 (OECD, s. d.). As projeções colocam o gigante asiático no topo do ranking de investimentos em P\&D até 2020 (OECD, 2015b). 
Mais recentemente, encontramos nas iniciativas tomadas pelos Estados Unidos após a crise financeira de 2007-2008 uma preocupação semelhante em implementar políticas de ciência e tecnologia como alavanca para a recuperação econômica. O American Recovery and Reinvestment Act (White House, 2010), aprovado pelo governo Barack Obama em 2009, estabeleceu diretrizes para o crescimento de longo prazo e alocou cerca de US\$ 700 bilhões para serem investidos na economia. Parte desse montante, cerca de US\$ 100 bilhões, foi destinada para programas de fomento à inovação. Nesse caso, as linhas mestras para a atuação do governo foram apresentadas na Strategy for American Innovation, que destacou, entre outras medidas necessárias, o apoio à pesquisa básica, a recursos humanos e infraestrutura, e a prioridade aos investimentos em energia limpa e saúde.

Em sua última versão (2015), a Strategy for American Innovation reafirmou os principais compromissos elencados na primeira edição, como o fomento ao desenvolvimento tecnológico e os investimentos em educação, com ênfase nas engenharias, em ciências e matemática. Essa estratégia contribuiu decisivamente para o aumento observado nos investimentos em P\&D, de US\$ 59 bilhões para US\$ 68 bilhões, entre 2008 e 2014 (OECD, 2014, p.444).

Mais ainda, a partir dessa iniciativa, outros programas foram criados pelo governo para fortalecer a trajetória de inovação nas empresas, como a National Network for Manufacturing Innovation (NNMI), cujo objetivo central, inspirado na experiência dos institutos Fraunhofer-Gesellschaft, da Alemanha, é apoiar parcerias entre universidades e empresas para o desenvolvimento de pesquisa aplicada, com vistas a solucionar problemas relevantes da indústria. O NNMI foi anunciado em 2012, com dotação orçamentária de US\$ 1 bilhão ao longo de dez anos. Desde então, já foram estabelecidas redes de pesquisa envolvendo dezenas de institutos para dedicarem-se ao desenvolvimento avançado da manufatura aditiva, novos materiais, fotônica e semicondutores, entre outros temas.

É digno de nota a crescente adoção de políticas guiadas pela demanda, as chamadas demand-side policies. Uma das principais são as encomendas públicas ou encomendas tecnológicas (ou public procurement for innovation). ${ }^{6}$ Entre as razões para a ênfase nesse tipo de instrumento estão as limitações à expansão (ou até a manutenção) do montante de orçamento público, que impõem igualmente maiores pressões sobre os impactos advindos dos recursos investidos. Ou seja, o cobertor mais curto intensifica a cobrança por resultados. Logo, para fechar a equação com saldo positivo, governos têm procurado mobilizar os instrumentos de fomento a produtos e serviços inovadores para responder a demandas sociais específicas (nas áreas de saúde, energia, mobilidade, segurança e alimentação, por exemplo). Utilizar as encomendas tecnológicas como um catalisador do desenvolvimento tecnológico e da inovação é uma estratégia antiga, já adotada pelo Brasil em diferentes momentos (a Embraer é um exemplo) (Miranda, 2007), mas que parece voltar a ganhar espaço nas agendas políticas 
mais recentemente (dentro do permitido pelas regras da Organização Mundial do Comércio, a OMC).

A Alemanha é um dos países que se esforçam para manter estáveis os investimentos em pesquisa e desenvolvimento (acima de $2,5 \%$ do PIB), ao mesmo tempo em que buscam tirar maior proveito das políticas de compra. ${ }^{7}$ Destacam-se três pontos como sinais desse maior interesse: primeiro, o acordo firmado entre seis ministérios (economia, defesa, transporte, meio ambiente, pesquisa e interior) visando, entre outros fins, tornar públicas suas demandas de longo prazo, identificar tecnologias potenciais e fomentar o diálogo entre suas agências; segundo, a revisão da legislação de compras públicas; terceiro, a criação de um centro de excelência (Centre of Excellence on Public Procurement) dedicado a colaborar com os agentes de governo na definição de políticas de compra que incentivem a inovação (OCDE 2014; Ministério de Economia e Energia).

Vale lembrar ainda o número de países que tem implementado medidas para simplificar e agilizar o acesso das empresas às linhas de apoio do Estado, como redução de exigências para acesso a recursos e integração de programas e instituições. Em síntese, diversos países têm dedicado, sistematicamente, um lugar especial à inovação entre suas prioridades políticas. Isso significa não apenas disponibilizar recursos e infraestrutura, mas também rever continuamente os instrumentos de modo a adequá-los às necessidades de cada período. Nesse sentido, como sugerem os relatórios da Organização para a Cooperação e Desenvolvimento Econômico (OCDE), a queda observada nos gastos em P\&D, em parte pode ter sido mitigada justamente pelos investimentos realizados por alguns países a fim de manter seu compromisso com a pesquisa e inovação, inclusive nos momentos de crise.

$\mathrm{O}$ Brasil tem muito a aprender com essas experiências. As atenções e o foco em educação, ciência e tecnologia, tanto em volume quanto em qualidade, devem obedecer à mesma lógica, por fazerem parte do nosso passaporte para $\mathrm{o}$ futuro. Quanto mais avançada for a produção científica e tecnológica e quanto mais preparados estiverem nossos pesquisadores, maior será a possibilidade de se aumentar a capacidade inovadora das empresas. Na mesma chave, quanto mais educada e qualificada for nossa população, maiores serão as chances de renovação e evolução da estrutura social brasileira.

Essa foi uma das lições que a China mais aprendeu.

Nos últimos trinta anos, alavancado por investimento pesado em infraestrutura e políticas públicas agressivas de aprendizagem e absorção de tecnologias, o parque produtivo chinês cresceu aceleradamente ao ponto de responder por quase um quarto da manufatura mundial em 2016 (A participação da China na indústria mundial era de 3\% em 1990 segundo The Economist, 2015).

$O$ peso, o tamanho e a qualidade da expansão chinesa modificaram a maneira como a indústria se desenvolveu ao longo do século XX. Ao mesmo tempo que seu crescimento acelerou a globalização, o peso de sua economia mexeu 
com os termos de troca e beneficiou grande parte dos países em desenvolvimento (em especial o Brasil), que ganharam musculatura ao serem chamados para atender nova demanda vinda da Ásia. É bom não esquecer, porém, que no mesmo período, as exportações de produtos de alto valor agregado, em especial da América Latina, caíram sensivelmente, juntamente com os empregos qualificados desse segmento. Em outras palavras, enquanto exportava commodities, a participação dos países latino-americanos nas exportações industriais caiu significativamente, assim como diminuiu a diversificação de sua pauta de bens manufaturados (Guajardo; Molano; Sica, 2016). Ou seja, a cooperação com a China exige apenas mais do que uma estratégia comercial, pois parceria, nesse caso, vem atrelada à competição. E a (des)atenção com tecnologia e inovação pode condenar - ou não - a economia à tradicional dependência das commodities. Que lições extrair?

Nesses mesmos trinta anos, o Brasil escorregou no crescimento e oscilou na elaboração e implementação de políticas marcadas pela busca de um padrão produtivo superior, alicerçado na inovação. Dois programas executados nos últimos anos, com focos e objetivos diferentes, quando não contraditórios, dão a dimensão de nossas dificuldades.

Os planos Brasil Maior (2011) e o Inova Empresa (2013) ganharam destaque em anos recentes. O primeiro, anunciado em 2011 como uma política industrial moderna, foi, de fato, dada a frágil concepção de sua rede de incentivos e subsídios, regressivo do ponto de vista da inovação, além de predatório no âmbito fiscal (Arbix, 2016). O Plano Inova Empresa, anunciado em 2013 e implementado basicamente pela Finep e pelo Bndes, foi desenhado como o primeiro programa inteiramente dedicado à inovação. Institucionalmente articulado, contou com a participação de diversos ministérios e agências, tanto na sua elaboração e execução quanto na dotação de recursos. O programa descentralizou o apoio para a inovação e conseguiu uma inédita integração de instrumentos (crédito, a subvenção econômica, grants para universidades e, em menor grau, a participação acionária). Com essa nova arquitetura, diferenciou-se no panorama das políticas públicas (Arbix; De Negri, 2014).

Por seu caráter efêmero, pelo despreparo dos órgãos de governo, pela imprecisão de objetivos e, principalmente, pelas graves limitações e desequilíbrio entre seus instrumentos (o plano foi sustentado em mais de $80 \%$ pela oferta de crédito subsidiado) o Inova Empresa teve, porém, seu alcance comprimido e circunstanciado.

Apesar de ter elevado o patamar das políticas públicas de desenvolvimento tecnológico no país, o Plano inova Empresa atuou apenas na dimensão do financiamento sem conseguir articulação com uma estratégia de conjunto voltada para alterar a base produtiva da indústria brasileira. Ou seja, os problemas ligados à inovação não encontrarão respostas convincentes apenas com maior fluência e barateamento do crédito, por mais importantes que sejam. 
Em outras palavras, o sucesso do plano Inova Empresa, de modo indireto, chama atenção para a necessária execução de uma política de conjunto, multi-institucional, baseada na articulação entre o público e o privado e que não flutue ao sabor das dificuldades da política macroeconômica. Pois sem o equacionamento do déficit estrutural da indústria brasileira, de modo a impulsionar avanços de qualidade no sistema de formação de pessoas, na infraestrutura, no ambiente de negócios, modelagem tributária e no incentivo ao surgimento e desenvolvimento de pequenas empresas (Barbosa; Borça; Horta; Cunha; Maciel, 2017), o país não conseguirá superar sua tradicional condição de seguidor em matéria de tecnologia.

\section{Como mudar}

O Brasil tem sérias dificuldades de persistir por um longo período em suas políticas públicas, mesmo quando mostram consistência. Ciclos eleitorais e a ação predatória que ainda marca grande parte das elites políticas do país, frequentemente levam governos a se afastarem dos interesses nacionais e a substituir programas contemporâneos por alternativas antigas que ressurgem constantemente no seio do governo e da sociedade. O Brasil exibe recaídas frequentes, mas precisa - e pode - se superar ao buscar obstinadamente o diálogo para a definição de estratégias de desenvolvimento que incluam, de modo especial, a tecnologia e a inovação como um de seus principais capítulos.

Em alguns momentos abriram-se frestas de esperança com a formulação de políticas públicas com foco na inovação (Miranda; Mirra, 2012). Mas, ao longo dos anos, esse foco se desfez e cedeu lugar à reprodução de velhas políticas, que flertaram com o protecionismo e a tutela estatal. Se é certo que a batalha pela inovação e tecnologia no Brasil avançou muito, também é verdade que ainda há um longo caminho pela frente.

O Estado precisa equipar-se para dar conta dos novos desafios colocados pelas mudanças tecnológicas que sacodem as economias pelo mundo afora. As universidades e centros de pesquisa precisam amadurecer e se livrar do peso do preconceito contra a inovação. E as empresas, mais do que nunca, devem redobrar seus esforços para aumentar o investimento privado em tecnologia. Sem essa união de esforços, a economia brasileira continuará patinando, ou mesmo regredirá para posições cada vez mais secundárias.

As janelas de oportunidade para os países em desenvolvimento fecham-se mais a cada dia. A concorrência por custo, qualidade e salário, com enormes sacrifícios para a população, está com seus dias contados. A revolução em curso no universo da produção, com impactos diretos no mercado de trabalho - modificando profissões, transformando ocupações e aumentando a concorrência entre trabalhadores e a desigualdade entre os mais e os menos qualificados -, é fonte ainda de maior instabilidade para as sociedades.

Para além das crises e oscilações conjunturais, o Brasil precisa de uma agenda clara para elevar a ambição e o impacto da CT\&I, aumentar o P\&D nas 
empresas e diversificar ainda mais o sistema nacional de inovação. Essa é a síntese deste estudo, que tem a pretensão de contribuir para a construção de uma agenda de longo prazo para a inovação brasileira.

A diminuição da distância que separa a indústria brasileira das práticas internacionais mais avançadas é desafio número um, que exige uma reflexão profunda sobre o modelo atual de produção de CT\&I no país, de modo a abrir caminho para novas lógicas, com outra escala e um remodelado e mais diversificado sistema de financiamento. E, o mais importante, em conexão com os avanços de CT\&I que sacodem hoje o mundo.

Por mais paradoxal que possa parecer, os momentos de crise são os mais apropriados para se evitar a diluição da centralidade que educação, ciência, tecnologia e inovação (CT\&I) têm para países como o nosso.

Muitos países avançados - e também os concorrentes mais diretos, como Índia, China, África do Sul e outros - preparam-se aceleradamente para participar da próxima onda que anuncia uma revolução no modo de produção industrial. Esse futuro acena com uma indústria avançada, que se caracteriza por maior dependência das tecnologias de informação e comunicação, pelo uso de equipamentos e máquinas mais conectados em redes (inclusive robôs), pelo controle descentralizado e pela operação de quantidades de informações em volume muito superior ao que estamos acostumados nos dias de hoje (big data). O debate é urgente.

\section{Notas}

1 No entanto, excluídos os gastos com pós-graduação, o setor empresarial lidera os investimentos.

2 Em 2017, o MCTIC passou a contar com cerca de R\$2,8 bilhões de orçamento, o equivalente a um terço do valor disponível em 2010. A se confirmar a previsão orçamentária para 2018, o ministério poderá dispor de um orçamento cerca de $40 \%$ menor do que o atual.

3 A partir de discussões entre empresas, associações empresariais e instituições de pesquisa, com apoio do governo, foi lançada a plataforma Industrie 4.0 (2013), que propõe diretrizes para a Alemanha perseguir, de modo a garantir liderança na produção de bens de capital e manter posição de destaque entre os fornecedores globais de tecnologias para o novo conceito de fábrica que está surgindo.

4 Com base nas recomendações do Conselho de Ciência e Tecnologia e do Comitê de Tecnologia e Inovação da Casa Branca, o governo Barack Obama lançou, em 2011, a Advanced Manufacturing Partnership (AMP), definida como um esforço nacional para unir o governo federal, as indústrias e a academia em prol do desenvolvimento de tecnologias que preparem o país para a indústria do futuro. Como desdobramento dessa iniciativa, foi criada a Rede Nacional de Institutos para Inovação na Manufatura, que visa promover centros de excelência, operados e financiados conjuntamente pelos setores público e privado, para o desenvolvimento de pesquisas e tecnologias que respondam a desafios da indústria. Essa experiência será comentada mais adiante neste texto. 
5 De forma sintética, os selos Industrie 4.0 e Advanced Manufacturing são utilizados correntemente como sinônimos. Não são. Ambos remetem aos esforços para acelerar os processos de digitalização. No conceito alemão, o foco recai sobre a integração da produção fabril. Na visão americana, a abordagem é mais ampla, considerando, entre outros aspectos, a busca por maior integração universidade-empresa para o desenvolvimento de tecnologias emergentes em áreas como materiais avançados. Foge ao escopo deste trabalho um mergulho nos diferentes conceitos. Para avançar mais, ver: Howaldt. Kopp e Schultze (2017, p.45-60).

6 Estima-se que as compras regulares dos governos (isto é, sem foco específico), representam cerca de $15 \%$ a $20 \%$ do Produto Interno Bruto (PIB) nos países avançados (Edquist et al., 2015). Ou seja, há grande potencial para fomentar produtos e serviços modernos e inovadores.

7 Segundo o Ministério de Economia e Energia alemão, os dispêndios contratuais do país atingem aproximadamente 300 bilhões de euros anuais.

\section{Referências}

ACADEMIA BRASILEIRA DE CIÊNCIAS. Por uma politica de Estado para Ciência, Tecnologia e Inovação: contribuições da ABC para os candidatos à Presidência do Brasil. Rio de Janeiro, 2014. Disponível em: <http://www.abc.org.br/IMG/pdf/doc-5793. pdf>.

ACEMOGLU, D.; RESTREPO, P. The race between machine and man: implications of technology for growth, factor shares and employment. Cambridge: NBER Working Paper Series 22252, May 2016

ANDREWS, D.; CRISCUOLO, C.; GAL, N. Frontier firms, technology diffusion and public policy: micro evidence from OECD countries. OECD Productivity Working Papers, 2015-02, OECD Publishing, Paris, 2015.

ARBIX, G. 2002-1014: Trajetória da inovação no Brasil. Análise n.17, Friedrich Ebert Stiftung Brasil, 2016.

ARBIX, G.; DE NEGRI, J. Chega de Saudades. Folha de S.Paulo, Tendências/Debates, 2.6.2014, p.3.

ARBIX, G.; VARON, J. Finlândia: o salto para uma economia baseada no conhecimento. In: ARBIX, A. et al. (Org.) Estratégias de inovação em sete países: EUA, Canadá, Irlanda, França, Reino Unido, Finlândia e Japão. Brasília: ABDI, 2009. p.156-185. Disponível em: <http://www.abdi.com.br/Estudo/MOBITnovofinal.pdf>.

BARBOSA, R.; BORÇA, G.; HORTA, G.; CUNHA, J.; MACIEL, F. A indústria, o PSI, o Bndes e algumas propostas. Textos para Discussão, Rio de Janeiro, n.114, abril de 2017.

BRYNJOLFSSON, E.; McAFEE, A. Race against the machine: how the digital revolution is accelerating innovation, driving productivity, and irreversibly transforming employment and the economy. Research Brief. Cambridge: The MIT Center for Digital Business, 2012.

CHAIMOVICH, H. Avaliação e Impactos da Ciência Brasileira. Apresentação do CNPq na reunião da SBPC, 5.9.2016. Disponível em: <https://www.abc.org.br/IMG/pdf/ doc-6986.pdf. 
CIMOLI, M.; DOSI, G.; STIGLITZ, J. The political economy of capabilities accumulation: the past and future of policies for industrial development. In: Industrial Policy and Development. S. 1.: Oxford University Press, 2009. p.1-16.

DE NEGRI, J. Avançar ou avançar na política de inovação. In: BARBOSA et al. (Org.) Industria e desenvolvimento produtivo no Brasil. Rio de Janeiro: Elsevier: FGV, 2015.

DE NEGRI, F.; CAVALCANTE, L. R. (Org.) Produtividade no Brasil: desempenho e determinantes. Brasília: Ipea, 2014. v.1.

EDQUIST, C. et al. (Ed.) Public procurement for innovation. Cheltenham: Edward Elgar Publishing, 2015.

EXECUTIVE OFFICE OF THE PRESIDENT. National Science and Technology Council, Advanced Manufacturing: National Strategic Plan. 2012.

FEDERAL MINISTRY FOR ECONOMIC AFFAIRS AND ENERGY. Fostering innovation through public procurement. Disponível em: <http://www.bmwi.de/EN/ Topics/Technology/Strong-policy-framework/fostering-innovation-through-public-procurement.html>.

GEREFFI, G. Global value chains in a post-Washington Consensus world. Review of International Political Economy, v.21, n.1, p.9-37, 2014.

GEREFFI, G.; LEE, J. Why the World Suddenly Cares About Global Supply Chains. Journal of Supply Chain Management, v.48, n.3, p.24-32, 2012.

GRABOWSKI, R. Premature deindustrialization and inequality, International Journal of Social Economics, v.44, n.2, p.154-68, 2017.

GROUP OF THE INDUSTRY-SCIENCE RESEARCH ALLIANCE. Recommendations for implementing the strategic initiative Industrie 4.0. 2013. Disponível em: <http://www.acatech.de/fileadmin/user_upload/Baumstruktur_nach_Website/ Acatech/root/de/Material_fuer_Sonderseiten/Industrie_4.0/Final_report_Industrie_4.0_accessible.pdf>.

GUAJARDO, J.; MOLANO, M.; SICA, D. Industrial Development in Latin America. What is China's Role?. Washington, DC: Atlantic Council, 2016.

HARAGUCHI, N.; CHENG, C.; SMEETS, E. The importance of manufacturing in economic development: Has this changed? Working Paper 01/2016. Dept. of Policy Research and Statistics. Viena: UNIDO, 2016.

HOWALDT, J.; KOPP, R.; SCHULTZE, J. Why Industrie 4.0 Needs Workplace Innovation - A Critical Essay About the German Debate on Advanced Manufacturing. Workplace Innovation, Springer, Cham, p.45-60, 2017.

JORGENSON, D.; HO, M.; SAMUELS, J. Education, participation, and the revival of U.S. Economic Growth. NBER Working Paper no 22.453, July 2016.

LEMA, R.; QUADROS, R.; SCHMITZ, H. Reorganising global value chains and building innovation capabilities in Brazil and India. Research Policy, v.44, n.7, p.1376-86, 2015 .

LOCKE, R.; WELlHAUNSEN, R. (Ed.) Production in the Innovation Economy. Cambridge: MIT Press, 2014.

MAPI. Manufacturers Alliance for Productivity and Innovation. A Changing China in 
an Unsettled World. Arlington: 23.1.2017. Disponível em: <https://www.mapi.net/ blog/2017/01/changing-china-unsettled-world>.

MCTI. Consolidação das recomendações da $4^{\text {a }}$ Conferência Nacional de Ciência e Tecnologia e Inovação para o Desenvolvimento Sustentável. In: CONFERÊNCIAS NACIONAL, REGIONAIS E ESTADUAIS e Fórum Municipal de CT\&I. Brasília: Ministério da Ciência e Tecnologia / Centro de Gestão e Estudos Estratégicos, 2010.

MCTI. Nota Informativa sobre Evolução dos dispêndios nacionais em CÉT e PÉD no período 2000 a 2013. Brasília, 2015. Disponível em: <http://www.mct.gov.br/upd_ blob/0237/237332.pdf>.

MCTIC. Indicadores Nacionais de C.TéI, 2017. Disponível em: <http://www.mct. gov.br/index.php/content/view/740.html>.

MIRANDA, Z. O voo da Embraer: a competitividade brasileira na indústria de alta tecnologia. São Paulo: Papagaio, 2007.

MIRANDA, Z.; MIRRA, E. Trajetórias do desenvolvimento no Brasil. Revista USP, n.93, 2012. Disponível em: <http://www.revistas.usp.br/revusp/article/viewFile $/ 45000 / 48613>$.

NATIONAL ECONOMIC COUNCIL. A Strategy for American Innovation: Driving Towards Sustainable Growth and Quality Jobs. 2009. Disponível em: <https://www. whitehouse.gov/administration/eop/nec/StrategyforAmericanInnovation>.

OECD. Policy Responses to the Economic Crisis: Investing in Innovation for Long-Term Growth. Paris, 2009. Disponível em: <http://www.oecd.org/sti/42983414.pdf>.

United States. OECD Science, Technology and Industry Outlook 2014. Paris: OECD Publishing, 2014.

Innovation Policies for Inclusive Growth. Paris: OECD Publishing, 2015a.

OECD Science, Technology and Industry Scoreboard 2015. Paris: OECD Publishing, 2015b. Disponível em: <http://www.keepeek.com/Digital-Asset-Management/oecd/science-and-technology/oecd-science-technology-and-industry-scoreboard-2015_sti_scoreboard-2015-en\#pagel>.

OECD Statistics. Main Science and Technology Indicators. S. d. Disponível em: <http://stats.oecd.org/Index.aspx?DataSetCode=MSTI_PUB\#>.

PISANO, G. You Need an Innovation Strategy. Harvard Business Review, Cambridge, June 2015.

PISANO, G.; SHIH, W. Restoring American Competitiveness. Harvard Business Review, Cambridge, July-August, 2009.

. Producing Prosperity. Why America needs a Manufacturing Renaissance. Harvard Business Review Press, Boston, 2012.

PNUD. Índice de Desenvolvimento Humano Municipal Brasileiro. Brasília: PNUD, Ipea, FJP, 2013.

RODRIK, D. Journal of Economic Growth, v.21, n.1, p.1-33, 2016.

SCImago Journal \& Country Rank. Disponível em: <http://www.scimagojr.com>.

THE ECONOMIST, Made in China. Print Edition, March 12 $2^{\text {th }}, 2015$. 
WHITE HOUSE. The Recovery Act: Transforming the American Economy Through Innovation, 2010. Disponível em: <https://www.whitehouse.gov/sites/default/files/ uploads/Recovery_Act_Innovation.pdf>.

WORLD BANK. Global Economic Prospects: Divergences and Risks. Washington, DC: World Bank, June 2016.

RESUMO - A crise que corrói o Brasil dificulta a retomada do crescimento e a elevação do patamar de competitividade da economia. A situação se torna mais grave quando confrontada com o avanço tecnológico que toma corpo nos países avançados e em desenvolvimento e que prenunciam mudanças profundas nas economias e na organização da sociedade. É urgente que o Brasil tenha condições básicas para não se distanciar ainda mais desse novo ciclo tecnológico. Este artigo, com base na experiência internacional, defende que, paradoxalmente, nos momentos de crise é que os países e empresas mais precisam aumentar seu investimento em inovação. Mais ainda, sugere que o Estado precisa se articular com a iniciativa privada, de modo a formar uma coalização entre empresas, universidades e governo, para enfrentar os desafios tecnológicos que sacodem as economias pelo mundo afora. Essas novas tendências, ainda inacessíveis à maior parte dos países emergentes, apontam para a formação de uma nova economia, articulada em torno de três grandes pilares: digitalização, integração e automação. É urgente a definição de estratégias de longa duração para que o país recupere protagonismo internacional e se destaque por sua inteligência e capacidade de fazer CT\&I de alta qualidade. PALAVRAS-CHAVE: Inovação, Produtividade e P\&D, Tecnologia, Economia digital, Estratégia de inovação.

ABSTRACT - The current Brazilian crisis undermines the country's economic recovery and its efforts to increase competitiveness. When confronted with technologies that are bringing about deep changes in the economy and in the organization of societies, the Brazilian situation seems to be even more disadvantageous. Brazil must urgently reduce the gap between its own technological capabilities and that of advanced countries. This article draws upon international experience and argues that, precisely in moments of crisis, countries and companies need to increase investment in innovation. Moreover, it suggests that the State must articulate with the private sector to form a coalition between enterprises, universities and government to face the technological challenges that are shaking economies around the world. These new trends, still inaccessible to most emerging countries, point to the formation of a new economy, based on three main pillars: digitization, integration and automation. Brazil must urgently define long-term strategies that push the country forward to regain international prominence and stand out for its intelligence and high quality science, technology and innovation.

KEYWORDS: Innovation, Productivity and R\&D, Technology, Digital economy, Innovation strategy.

Glauco Arbix é professor titular do Departamento de Sociologia da Faculdade de Filosofia, Letras e Ciências Humanas da USP, pesquisador do Observatório da Inovação do Instituto de Estudos Avançados da USP. @ - glaucoarbix@gmail.com 
Zil Miranda é doutora em Sociologia pela Universidade de São Paulo e especialista em desenvolvimento industrial da Diretoria de Inovação da Confederação Nacional da Indústria. @ - zilmmiranda@gmail.com

Recebido em 17.7.2017 e aceito em. 2.8.2017.

I Departamento de Sociologia, Faculdade de Filosofia, Letras e Ciências Humanas, Universidade de São Paulo, São Paulo, São Paulo, Brasil.

II Confederação Nacional da Indústria, São Paulo, São Paulo, Brasil. 